\title{
Analgesic Effects of Additional Nitroglycerine in Intravenous Regional Lidocaine-Based Anesthesia Through Forearm Surgery
}

\author{
Maziyar Mahjoubifard, ${ }^{1}$ Hasan Enayati, ${ }^{2}$ Touraj Babaee, ${ }^{3}$ Mehdi Heidari, ${ }^{2}$ and Alireza \\ Jahangiri Fard ${ }^{4, *}$ \\ ${ }^{1}$ Department of Anesthesiology, Fellowship in Cardiac Anesthesiology, Children and Adolescents' Health Research Center, Zahedan University of Medical Sciences, Zahedan, IR Iran \\ ${ }^{2}$ Deoartment of Anesthesiology, Children and Adolescents' Health Research Center, Zahedan University of Medical Sciences, Zahedan, IR Iran \\ ${ }^{3}$ Rajaie Cardiovascular Medical and Research Center, Iran University of Medical Sciences, Tehran, IR Iran \\ ${ }^{4}$ Lung Transplantation Research Center, National Research Institute of Tuberculosis and Lung Diseases (NRITLD), Shahid Beheshti University of Medical Sciences, Tehran, IR Iran \\ ${ }^{*}$ Corresponding author: Alireza Jahangiri Fard, Lung Transplantation Research Center, National Research Institute of Tuberculosis and Lung Diseases (NRITLD), Shahid Beheshti \\ University of Medical Sciences, Tehran, IR Iran. Tel:+98-2126109644, E-mail: alirezajahangiri@sbmu.ac.ir
}

Received: March 1, 2015; Accepted: May 15, 2015

Background: Intravenous regional anesthesia (IVRA) (or Bier's block) is the administration of a local anesthetic drug to an organ intravenously, when compressed by tourniquet. Simple use in outpatient and emergency settings, being regional instead of general anesthesia and having reasonable costs make IVRA most acceptable.

Objectives: Nitroglycerine, as a safe and available medication, was evaluated by the current study in the search for better analgesia withlower complications that plays the role of a suitable adjuvant in regional anesthesia by lidocaine.

Patients and Methods: Through a randomized controlled clinical trial, two types of anesthesia were used regionally for 70 cases of forearm surgery between 2010 and 2011. Elective cases of forearm surgery with American Society of Anesthesiologist (ASA) class I or II were enrolled in the study and were randomly divided to two groups of cases and controls. For the control group, lidocaine was used alone for IVRA while for the intervention group lidocaine as well as $200 \mu \mathrm{g}$ of nitroglycerin was used through the procedure.

Results: On average, sensory block started in 3.48 and 6.5 minutes, for the case and control groups, respectively. The mean motor block time was 4.18 and 6.98 minutes for the cases and controls, respectively. The groups differed in terms of times required for sensory and motor blocks. Recovery time was longer among cases (118.32 \pm 7.8 minutes) when compared to the controls.

Conclusions: Nitroglycerin at a dose range between 200 and $400 \mu \mathrm{g}$, as an adjunct for lidocaine, can evidently improve regional anesthesia, increase block recovery time and postpone the need for postoperative analgesics, especially opioids.

Keywords: Intravenous Regional Anesthesia; Lidocaine; Nitroglycerin; Forearm Closed Fracture; Analgesic Effects

\section{Background}

Initially, Intravenous Regional Anesthesia (IVRA) was introduced by Bier in 1908; at this pointprocaine was used and lidocaine was later introduced by Holmes (1). Intravenous Regional Anesthesia (or Bier's block) is mainly the administration of a local anesthetic drug to an organ intravenously, when compressed by tourniquet. It is based on drug distribution to no vessel tissues,such asaxons and nerve terminations. Simple use in outpatient and emergency settings, being regional instead of general anesthesia and having reasonable costs make IVRA most acceptable (2). Otherwise, toxicity, slow effects initiation, weak muscular relaxation, pain due to tourniquet and weak postoperative analgesia are the main limitations (3). To improve effects, adjuncts were recently added to anesthetic solutions among which opioids, non steroidal inflamatory drugs (NSAIDs), $\alpha_{2}$-agonists and neostigmine are the most commonly used (1).

Nitroglycerine, through increasing CGMP in the peripheral and central nervous system, results in pain ad- justment besides an increase in the effects of pain-killers in acute and chronic pain, such as its impacts on cancer pain control (4).

In orthopedics, for elderly, comorbidities and trauma, general is not preferred over regional anesthesia, considering postoperative effectiveness, shorter hospital stay and lower complications and costs for the latter.

\section{Objectives}

Nitroglycerine, as a safe and available medication, was evaluated by the current study in the search for better analgesia with lower complications to play the role of a suitable adjuvant in regional anesthesia by lidocaine.

\section{Patients and Methods}

Through a randomized controlled clinical trial, two types of anesthesia were used regionally for cases of forearm surgery between 2010 and 2011.

Copyright (C) 2015, Shahid Beheshti University of Medical Siences. This is an open-access article distributed under the terms of the Creative Commons AttributionNonCommercial 4.0 International License(http://creativecommons.org/licenses/by-nc/4.0/) which permits copy and redistribute the material just in noncommercial usages, provided the original work is properly cited. 


\subsection{Patients}

Elective cases of forearm surgery with ASA classes I and II, who had referred to Khatam-ol-Anbia hospital of Zahedan, a city in the South East of Iran, within the duration of the study, were enrolled considering the inclusion and exclusion criteria. The candidates were then randomly divided to two groups of cases and controls. The sample size of 35 individuals per group was calculated via the following equation. The power of study was 0.8 .

$$
n=\frac{\left(z_{1}-\frac{\alpha}{2}+z_{1}-\beta\right)^{2}\left(s_{1}{ }^{2}+s_{2}{ }^{2}\right)}{\left(X_{1}-X_{2}\right)^{2}}
$$

$\mathrm{z}_{1}=1.62 ; \overline{\mathrm{x}}_{1}=2.18 ; \mathrm{z}_{2}=1.53 ; \overline{\mathrm{x}}_{2}=3.56$.

The participants were all cases of close reduction of forearm fractures, aged between 20 and 50 years. The patients were excluded if they were cases of Raynaud's phenomenon or if they had ahistory of using several drug formsof nitroglycerine including nitrocontin, isordil and sublingual Nitroglycerin (TNG), history of sildenafil use in the previous 24 hours, or a history of asthma or antihypertensive medications use. All the patients were informed of the value of the study, conventional technique and interventional activities, and necessary parts of the procedure before giving their informed consent.

\subsection{Preoperative Procedure}

After preoperative assessment, patients were transported to the operation room where vital signs and SpO2 were monitored and recorded.

An intravenous cannula was set on the opposite forearm in order to administrateany premedication including fentanyl $(1 \mu \mathrm{g} / \mathrm{kg})$ and midazolam (0.015 mg/kg).All the patients received $5 \mathrm{mg} / \mathrm{kg}$ of crystalloid solutions before anesthesia initiation.

To provide IVRA, a cannula was embedded in the main vein on the backside of the hand before raising the upper extremity for five minutes while using smarch for organ regional blood evacuation. A pneumatic tourniquet was now fastened around the patient's arm with $250 \mathrm{mmHg}$ pressure in its proximal cuff.

Anesthetic drug was slowly injected through the cannula on the hand during 90 minutes by a person blinded to the study. The drug was $3 \mathrm{mg} / \mathrm{kg}$ of lidocaine diluted in $0.5 \%$ normal saline for controls and $3 \mathrm{mg} / \mathrm{kg}$ of lidocaine in addition to $200 \mu \mathrm{g}$ of nitroglycerine in a similar dilution ratio for the invention group. Ulnar, median and radial dermatomes of upper extremities were checked for sensory block initiation with a bevel 22 gauge needle every 30 seconds, immediately after injection and the results were recorded. Motor block was evaluated based on the patient's ability of flexion and extension of their wrist and fingers to record motor block initiation time.

The surgery was started when sensory and motor blocks were completed and the distal tourniquet was inflated to $250 \mathrm{~mm} \mathrm{Hg}$ before deflating the proximal tourniquet.

\subsection{Pain Assessment}

Tourniquet-induced pain was assessed using a VAS for which score " 0 " meant absolutely no pain while score "10" meanta pain so intense that has never been experienced before. Through the procedure, we used $1 \mu \mathrm{g} / \mathrm{kg}$ of intravenous fentanyl for pain relief at VAS $>3$. Visual Ana$\log$ Scale was assessed every five minutes for 40 minutes.

Tourniquet was not removed before 30 minutes. Cuff deflations took 10 minutes. Patient's pain, heart rate (HR) and blood pressure (BP) were also assessed after tourniquet removal at 30 minutes and 2, 4, 6, 12 and 24 hours. In the case of pain with VAS score of $>3,30 \mathrm{mg}$ of intramuscular opioids, like pethidine was administered, while recording the daily dose of pethidine.

\section{Results}

A total number of 70 patients were enrolled in the trial, which were candidates for elective surgery of forearm. Males were the majority of the two groups (total of 63 males versus 7 females). The mean \pm standard deviation (SD) of age was $31.63 \pm 10.88$ for the cases and $32.47 \pm 12.63$ for the controls. There was no statistical difference between the two groups in terms of sex and age distribution ( $P$ value $>0.05$ ). Table 1 shows age and gender information of the participants.

On average, sensory block started after 3.48 and 6.5 minutes in the case and control groups, respectively. The mean motor block time was 4.18 and 6.98 minutes for cases and controls, respectively. The groups differed in terms of times needed for sensory and motor blocks (P value < 0.001 ) as indicated by Table 2 .

Time until the first postoperative dose of painkiller was needed (recovery time) is illustrated in Table 1 . This time was longer among cases (118.32 \pm 7.8 minutes) when compared to the controls (32.28 \pm 21.2 minutes) (Pvalue $<0.001$ ).

As indicated by Figure 1, the mean pain score differed between the two groups (Pvalue $<0.001$ for all) 2, 6,12 and 24 hours after the procedure, especially at two hours after surgery.

The mean opioid dose was $50 \pm 10.11 \mu \mathrm{g}$ and $110 \pm 22 \mu \mathrm{g}$ for cases and controls, respectively with the difference being statistically significant (P value $<0.001, t=14.66$ ).

When patients' heart rate and blood pressure were studied, no difference was found between the two groups, as indicated by Figures 2 and 3 .

\begin{tabular}{lcc}
\hline \multicolumn{3}{l}{ Table 1. Age and Gender of the Participants } \\
\hline LID + NTG & LID \\
\hline Age & & \\
Mean \pm SD & $31.63 \pm 10.88$ & $32.47 \pm 12.63$ \\
Range & $20-50$ & $20-50$ \\
Gender & 32 & 31 \\
Male & 3 & 4 \\
\hline Female & & \\
\hline
\end{tabular}




\begin{tabular}{lcccc}
\hline \multicolumn{5}{l}{ Table 2. Sensory and Motor Block Onset } \\
\hline & LID \pm NTG & LID & Sig & T \\
\hline $\begin{array}{l}\text { Sensory block } \\
\text { onset, min }\end{array}$ & $3.48 \pm 0.99$ & $6.5 \pm 1.86$ & $<0.001$ & 8.48 \\
$\begin{array}{l}\text { Motor block } \\
\text { onset, min }\end{array}$ & $4.18 \pm 1.42$ & $6.98 \pm 0.91$ & $<0.001$ & 9.82 \\
$\begin{array}{l}\text { Recovery time } \\
\text { Opioid dose, } \\
\mu \text { g }\end{array}$ & $118.32 \pm 7.8$ & $34.28 \pm 21.2$ & $<0.001$ & 22.53 \\
\hline
\end{tabular}

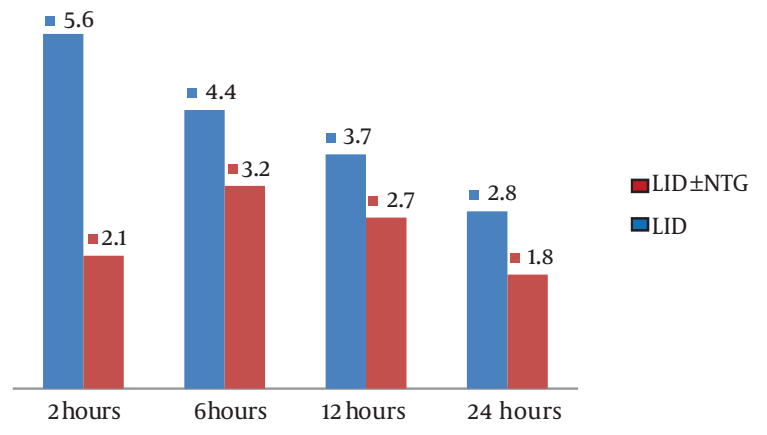

Figure 1. The Pain Score at Several Time Points After the Surgery

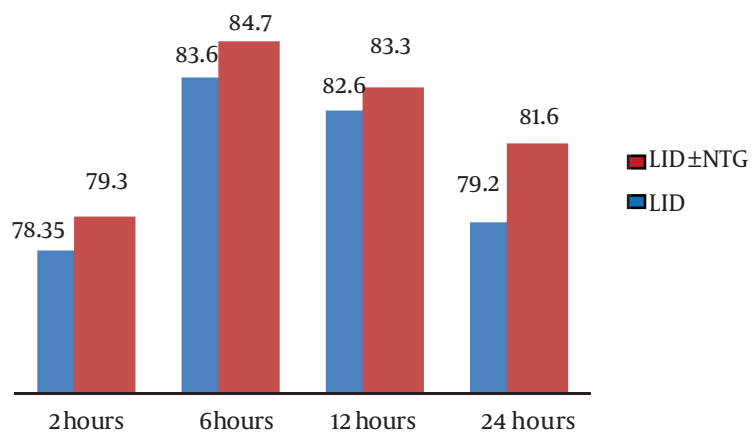

Figure 2. The Means of Heart Rate at Different Times

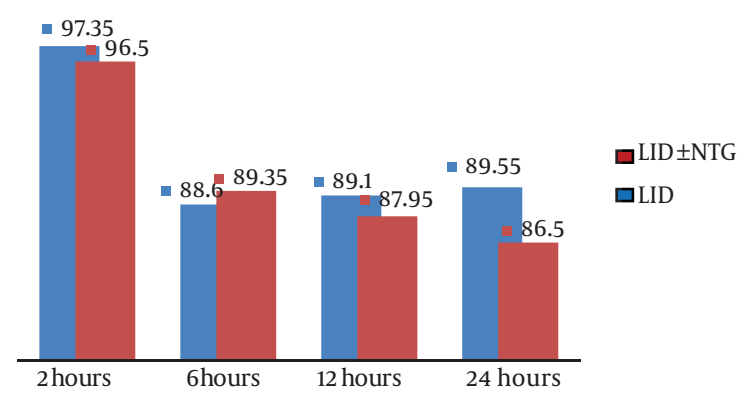

Figure 3. The Means of Blood Pressure After Surgery

\section{Discussion}

This trial focused on the analgesic effects of additive nitroglycerine to lidocaine-based regional anesthesia in forearm surgeries and was successful to show statistically better anesthesia without any side effects or surgical complications. During a similar study by Bansal et al. (5), 75 candidates of hand and forearm surgery were divided to three groups to evaluate the effects of magnesium and nitroglycerin, separately, as adjuvants for anesthesia added to lidocaine. The authors reported shorter sensory and motor block onset time in groups, which used each of the two adjuncts along with lidocaine compared to the group that received lidocaine alone. Magnesium had the earliest sensory block while nitroglycerin had the earliest motor block. This study found no additional side effects when nitroglycerine was used, as found by our trial.

Asadi and Mehri (6) conducted a double-blinded trial to evaluate the outcome of adding nitroglycerin to lidocaine in regional anesthesia ofupper extremities. Likely, this study reported shorter onset time of both sensory and motor block. These authors also showed longer sensory recovery time and lower frequency of opioid injection when the combination of lidocaine and nitroglycerin was used, as found by our study. One hundred cases of hand surgery were divided to four groups of control and interventions by Honarmand et al. (7) to evaluate the effects of different doses of nitroglycerin, which was added to lidocaine for regional anesthesia. They found that higher concentrations of nitroglycerin $(400 \mu \mathrm{g}$ added to $3 \mathrm{mg} / \mathrm{kg}$ of $2 \%$ lidocaine) shortened the sensory and motor onset times compared to lower doses (200 and 300 $\mu \mathrm{g})$. Although our study used $200 \mu \mathrm{g}$ of nitroglycerin plus conventional doses of lidocaine, which was half of that used by Honarmand et al. (7), it was enough for significantly different outcomes in block onset time and recovery time.

In another study by Skriapas et al. (8), 223 male candidates of prostate surgery benefited from glyceryltrinitrate ointment for perianal anesthesia in addition to lidocaine through the procedure of trans rectal ultrasonography (TRUS) as well as prostate biopsy.

Some studies have compared nitroglycerin with other analgesics and anesthetics, such asketamine in Elmetwaly's trial (9) for regional anesthesia. Sensory block onset in the nitroglycerin group was the same, which was reported in our study and the controls also experienced what we reported (3.5 and 6.5 minutes, respectively). Our trial showed longer motor block onset time than what was reported by Elmetwaly et al. (4.18 minutes versus 3.6 minutes). In our controls it took 6.98 minutes for the start of motor block whilst this duration was 10.2 minutes in Elmetwaly's trial.

Another Iranian study by Abbasivash et al. (10) concluded that nitroglycerin at $200 \mu \mathrm{g}$ dosage shortened the onset time of sensory and motor blocks. The authors obtained relatively better results in block onset times when 
compared to our trial. They also concluded significantly lower needs for postoperative fentanyl and meperidine.

Sen et al. (11) reported shortened onset times for sensory and motor block, which was lower than what we found.

They reported a mean of 225 minutes before the need for the first postoperative analgesic among their cases, which was longer than what our cases reported (118.32 minutes).

Similar to our results, as far as we know, all the trials, showed no more side effects than the classic and conventional technique, in which lidocaine is used alone.

To conclude, nitroglycerin at doses of 200 to $400 \mu \mathrm{g}$, as an adjunct for lidocaine, can improve regional anesthesia, increase block recovery time and postpone the need to postoperative analgesics, especially opioids.

\section{Authors' Contributions}

Study concept and design: Maziyar Mahjoubifard. Acquisition of data: Hasan Enayati, Mehdi Heidari. Analysis and interpretation of data:Touraj Babaee. Drafting of the manuscript: Alireza Jahangirifard

\section{References}

1. Choyce A, Peng P. A systematic review of adjuncts for intravenous regional anesthesia for surgical procedures. Can J Anaesth. 2002;49(1):32-45.

2. Strichartz GR, Berde CB. Local Anesthetics. In: Miller RD, editor.
Miller's Anesthesia. 7 ed. Philadelphia: Elsevier, Churchil Livingstone; 2010

3. Johnson CN. Intravenous regional anesthesia: new approaches to an old technique. CRNA. 2000;11(2):57-61.

4. Lauretti GR, Perez MV, Reis MP, Pereira NL. Double-blind evaluation of transdermal nitroglycerine as adjuvant to oral morphine for cancer pain management. J Clin Anesth. 2002;14(2):83-6.

5. Bansal P, Baduni N, Bhalla J, Mahawar B. A comparative evaluation of magnesium sulphate and nitroglycerine as potential adjuncts to lidocaine in intravenous regional anaesthesia. Int J Crit Illn Inj Sci. 2015;5(1):27-31.

6. Asadi HK, Mehri D. The analgesic effect of nitroglycerin added to lidocaine on quality of intravenous regional anesthesia in patients undergoing elective forearm and hand surgery. Acta Cir Bras. 2013;28(1):19-25.

7. Honarmand A, Safavi M, Fatemy A. The analgesic effect of three different doses of nitroglycerine when added to lidocaine for intravenous regional anesthesia in trauma patients. Ulus Travma Acil Cerrahi Derg. 2011;17(6):497-503.

8. Skriapas K, Konstantinidis C, Samarinas M, Xanthis S, Gekas A Comparison between lidocaine and glyceryl trinitrate ointment for perianal-intrarectal local anesthesia before transrectal ultrasonography-guided prostate biopsy: a placebo-controlled trial. Urology. 2011;77(4):905-8.

9. Elmetwaly KF, Hegazy NA, Aboelseoud AA, Alshaer AA. Does the use of ketamine or nitroglycerin as an adjuvant to lidocaine improve the quality of intravenous regional anesthesia? Saudi J Anaesth. 2010;4(2):55-62.

10. Abbasivash R, Hassani E, Aghdashi MM, Shirvani M. The effect of nitroglycerin as an adjuvant to lidocaine in intravenous regional anesthesia. Middle East J Anaesthesiol. 2009;20(2):265-9.

11. Sen S, Ugur B, Aydin ON, Ogurlu M, Gursoy F, Savk O. The analgesic effect of nitroglycerin added to lidocaine on intravenous regional anesthesia. Anesth Analg. 2006;102(3):916-20. 